\section{Temporary brittle bone disease: relationship between clinical findings and judicial outcome}

\author{
Colin R. Paterson, ${ }^{1}$ Elizabeth A. Monk ${ }^{2}$ \\ 1Late of Department of Medicine; 2School \\ of Business, University of Dundee, \\ Dundee, Scotland
}

\section{Abstract}

There is a wide differential diagnosis for the child with unexplained fractures including non-accidental injury, osteogenesis imperfecta and vitamin $\mathrm{D}$ deficiency rickets. Over the last 20 years we and others have described a selflimiting syndrome characterised by fractures in the first year of life. This has been given the provisional name temporary brittle bone disease. This work had proved controversial mostly because the fractures, including rib fractures and metaphyseal fractures, were those previously regarded as typical or even diagnostic of non-accidental injury. Some have asserted that the condition does not exist. Over the years 1985 to 2000 we investigated 87 such cases with fractures with a view to determining the future care of the children. In 85 of these the judiciary was involved. We examined the clinical and radiological findings in the 33 cases in which there was a judicial finding of abuse, the 24 cases in which the parents were exonerated and the 28 cases in which no formal judicial finding was made. The three groups of patients were similar in terms of demographics, age at fracturing and details of the fractures. The clinical similarities between the three groups of patients contrast with the very different results of the judicial process.

\section{Introduction}

The finding of fractures in a child that the parents or carers cannot explain causes immediate problems to medical and judicial authorities. One possibility is non-accidental injury, it being assumed that the parents are denying assaults that they or others have inflicted. A second possibility is some form of bone disease which causes fractures that are either spontaneous or occur with normal handling.

Various bone disorders have been recognised as causes of unexplained fractures in early childhood. The best known is osteogenesis imperfecta; a large group of inborn disorders, often but not always caused by defects in the molecular structure of collagen, the principal structural protein of bone. We and others have reported cases of osteogenesis imperfecta in which the diagnosis was not made early enough to prevent allegations of non-accidental injury. 1,2 The damage to a family, and not least the child itself, from such a mistaken diagnosis is very substantial.

A second disorder that can cause unexplained fractures and fracture-like appearances is vitamin D deficiency rickets. This too can lead to an incorrect initial diagnosis of nonaccidental injury. ${ }^{3,4}$ Similarly vitamin $\mathrm{C}$ deficiency (scurvy) may cause fractures and bruising which is misinterpreted as non-accidental injury. ${ }^{5}$ Scurvy is a disorder of collagen formation; vitamin $\mathrm{C}$ is essential for this process. Copper is also essential for collagen formation and copper deficiency has long been known to cause fractures both in man and in experimental animals. ${ }^{6}$ A similar biochemical mechanism underlies the finding of fractures mimicking those of non-accidental injury in Menkes' kinky hair disease.7,8 Fractures misinterpreted as evidence of non-accidental injury have also been described in biliary atresia, ${ }^{9}$ in propionic acidaemia ${ }^{10}$ and as a result of fetal immobility due to neuromuscular disease. 11 There is no reliable information on the frequency of any of these disorders; the impression that they are uncommon may simply reflect the infrequency with which they are considered in the differential diagnosis of a child with unexplained fractures. Since 1985 we and others have proposed the existence of a disorder, distinct from osteogenesis imperfecta that causes fractures and often very many fractures in the first year of life. It has been given the provisional name temporary brittle bone disease.12-16 This work has proved controversial mainly because the fractures, including rib fractures and metaphyseal fractures, are those previously thought to be typical or even diagnostic of non-accidental injury. Some have asserted that the condition does not exist.17,18 If such cases are not instances of non-accidental injury they form a remarkably consistent group, both clinically and radiologically. ${ }^{13,14}$ In all cases it was striking that the fractures were not accompanied by other commensurate evidence of injury such as bruising. In many there was good evidence from professional observers and others of such a discrepancy. Another pointer to the existence of a temporary brittle bone disease is the fact that a similar disorder causes fractures in infants in hospital in circumstances in which non-accidental injury is very unlikely. ${ }^{16}$ In addition children returned to their parents have not sustained subsequent non-accidental injury. 19

The cases investigated personally appeared to have strong clinical similarities to each other. Since the numbers were large we had an opportunity to examine the relationship between the clinical and radiological findings and the outcome of the judicial process in civil cases.
Correspondence: Colin R. Paterson, Temple Oxgates, Longforgan, Dundee DD2 5HS, Scotland, UK. Tel: +44.1382 .360240 .

E-mail: c.s.paterson@btinternet.com

Key words: temporary brittle bone disease, osteogenesis imperfecta, non-accidental injury, fractures, civil litigation.

Acknowledgements: the authors would like to thank Ms. Kirsteen Bovill for skilled secretarial help.

Conflicts of interests: CRP received normal fees for investigating some of the cases and, when needed, giving evidence in court.

Received for publication: 2 August 2011.

Accepted for publication: 13 September 2011.

This work is licensed under a Creative Commons Attribution NonCommercial 3.0 License (CC BYNC 3.0).

CC Copyright C.R. Paterson and E.A. Monk, 2011

Licensee PAGEPress, Italy

Pediatric Reports 2011; 3:e24

doi:10.4081/pr.2011.e24

\section{Materials and Methods}

Over the years 1985 to 2000 one of us (CRP) investigated 132 cases of unexplained fractures where the clinical and radiological features pointed to temporary brittle bone disease. Of these 104 had fractures as the principal or only problem; cases in which other concerns such as subdural bleeding were present will be described elsewhere. Of these patients the evaluation was primarily concerned with the future care of the child in 87 cases.

The 87 patients had been referred by legal representatives of the parents (73 cases), by a guardian ad litem (one case), by paediatricians (two cases), by general practitioners (six cases), by social workers (three cases) or by police officers (two cases).

In two cases the children remained with their parents without any judicial involvement. In the remaining 85 cases the jurisdictions involved were England and Wales (53 cases), United States (22 cases), Scotland (seven cases), Northern Ireland (one case), New Zealand (one case) and Sweden (one case).

In all cases CRP obtained a history from the parents or carers, parents being interviewed separately and together. In 78 cases this history was obtained in person; in the remaining seven cases it was obtained by telephone. In all cases copies of the x-rays were reviewed personally together with such medical records as were available. Detailed records were made of the clinical features and radiological findings. 
For the purpose of the current investigation the cases were subdivided according to the judicial outcome: 33 cases in which judicial findings of abuse were made, 24 cases in which the parents were exonerated and 28 cases resolved without any formal judicial findings. This last group included one case in which fractures had occurred in local authority foster care and, following a hearing, the child had been returned to her natural mother.

\section{Results}

Table 1 shows the principal demographic and clinical features of the patients. With one exception there were no significant differences between the patients in the three groups. The exception was in the number of metaphyseal fractures between the patients with a judicial finding of abuse and those whose parents were exonerated (two-tailed $\mathrm{P}$ value 0.019 )

Overall of the 85 cases described 63 were returned to their parents and some follow-up information was available on 61 . These findings are reported in detail elsewhere ${ }^{19}$ but, in summary, there were no subsequent allegations of non-accidental injury in any; the mean follow-up period was 6.9 years.

\section{Discussion}

In all the jurisdictions the standard of proof needed for a finding of non-accidental injury is a balance of probabilities. It is surprising therefore that, despite the novelty of the proffered diagnosis of temporary brittle bone disease, so many cases led to the exoneration of the parents, often despite energetic evidence in favour of a diagnosis of non-accidental injury. This fact does not just reflect the cogency of the arguments for some form of bone disease; other relevant evidence including the social background was usually taken into account.

The initial impetus for proposing the existence of a temporary brittle bone disease came from cases in the UK and the US in which very large numbers of fractures were found in early childhood without any commensurate evidence of injury in children reliably observed by non-family members. Osteogenesis imperfecta seemed unlikely since by the time the patients were investigated many months had passed and no further fractures found. Osteogenesis imperfecta severe enough to cause many fractures at three months of age would probably have caused further fractures. Non-accidental injury seemed equally unlikely because of the gross discrepancy between the radiological

Table 1. Demographic details and clinical findings in the three groups of patients.

\begin{tabular}{lccc} 
& $\begin{array}{c}\text { Judicial finding } \\
\text { of NAI }\end{array}$ & $\begin{array}{c}\text { Parents } \\
\text { judicially } \\
\text { exonerated }\end{array}$ & $\begin{array}{c}\text { No judicial } \\
\text { finding }\end{array}$ \\
Number of patients & 33 & 24 & 28 \\
Males/females & $20 / 13$ & $15 / 9$ & $15 / 13$ \\
\hline Gestation (weeks)* & $38.4(2.6)$ & $36.8(3.8)$ & $37.6(3.6)$ \\
Gestation <36 weeks & $3 / 33$ & $6 / 24$ & $5 / 28$ \\
\hline Birthweight (g) & $3102(723)$ & $2698(694)$ & $2989(836)$ \\
Age first fracture found (months) & $3.3(2.4)$ & $2.9(1.8)$ & $3.7(2.1)$ \\
\hline Total number of fractures* & $10.7(6.4)$ & $9.7(6.0)$ & $8.4(6.2)$ \\
Total number of fractures (range) & $3-25$ & $2-26$ & $1-32$ \\
\hline Number of rib fractures* & $5.7(5.7)$ & $7.4(5.6)$ & $4.7(5.5)$ \\
Number of rib fractures (range) & $0-20$ & $0-17$ & $0-25$ \\
\hline Number of diaphyseal fractures* & $1.5(1.3)$ & $0.8(1.3)$ & $1.6(1.5)$ \\
Number of diaphyseal fractures (range) & $0-4$ & $0-5$ & $0-5$ \\
\hline Number of metaphyseal abnormalities * & $3.3(3.6)$ & $1.4(1.8)$ & $2.0(3.0)$ \\
Number of metaphyseal abnormalities (range) & $0-18$ & $0-6$ & $0-14$ \\
\hline
\end{tabular}

*mean and standard deviation.

and clinical findings.

One difficulty in this field is that the features claimed for temporary brittle bone disease are also those widely regarded as typical or even pathognomonic for non-accidental injury. $20-23$ These views have been expressed for several decades and textbooks show radiological examples of non-accidental injury that could represent temporary brittle bone disease. For example metaphyseal fractures have often been regarded as the most characteristic radiological sign of non-accidental injury. The original evidence in support of this view may be limited and it is known that metaphyseal fractures and fracture-like appearances occur in a wide range of bone disorders in early childhood. $24-26$

The data presented here indicate that there were considerable similarities between the three groups of patients with, apparently, temporary brittle bone disease. The great difference in judicial outcome must therefore reflect non-clinical factors. Possible factors include the nature of the non-medical evidence, the quality of counsel and experts in both sides and the quality and lack of prejudice in the judges. The judicial arrangements may be significant. In two cases (in different states) in the US appeals with much new evidence were heard by the judges who had made the initial determinations. Both failed. In the UK the current practice is usually for all parties to appoint a single expert to investigate. While this may result in shorter hearings it is unlikely to ensure justice.

The causes of temporary brittle bone disease are not yet known. Possible factors include diminished fetal movement, hereditary influences, and biochemical factors including copper deficiency and vitamin $\mathrm{C}$ deficiency. 13,27
Pre-term birth is a significant contributory factor in all series but the link with fracture risk is still unclear. Much further work remains to be done but the lack of a recognised molecular cause should not delay the recognition of the likely existence of a temporary brittle bone disease.

\section{References}

1. Gahagan S, Rimsza ME. Child abuse or osteogenesis imperfecta: how can we tell? Pediatrics 1991;88:987-92.

2. Paterson CR, McAllion SJ. Classical osteogenesis imperfecta and allegations of nonaccidental injury. Clin Orthop Rel Res 2006;452:260-4.

3. Keller KA, Barnes PD. Rickets vs abuse: a national and international epidemic. Pediatr Radiol 2008;38:1210-6.

4. Paterson CR. Vitamin D deficiency rickets and allegations of non-accidental injury. Acta Paediatrica 2009;98:2008-12.

5. Paterson C R. Multiple fractures in infancy: scurvy or nonaccidental injury? Orthop Res Rev 2010;2:45-8.

6. Paterson CR, Burns J. Copper deficiency in infancy. J Clin Biochem Nutr 1988;4: 175-90.

7. Adams PC, Strand RD, Bresnan MJ, Lucky AW. Kinky hair syndrome: serial study of radiological findings with emphasis on the similarity to the battered child syndrome. Radiology 1974;112:401-7.

8. Bacopoulou F, Henderson L, Philip S G. Menkes' disease mimicking non-accidental injury. Arch Dis Child 2006; 91:919.

9. DeRusso PA, Spevak MR, Schwarz KB. 
Fractures in biliary atresia misinterpreted as child abuse. Pediatrics 2003:185-8.

10. Talbot JC, Gummerson NW, Kluge W, et al. Osteoporotic femoral fracture in a child with propionic acidaemia presenting as non-accidental injury. Eur $\mathrm{J}$ Pediatr 2006;165:496-7.

11. Rodriguez JI, Garcia-Alix A, Palacios J, Paniagua R. Changes in the long bones due to fetal immobility caused by neuromuscular disease. J Bone Joint Surg 1988;70-A:1052-60.

12. Paterson CR. Osteogenesis imperfecta and other bone disorders in the differential diagnosis of unexplained fractures. J Roy Soc Med 1990;83:72-4.

13. Paterson CR, Burns J, McAllion SJ. Osteogenesis imperfecta: the distinction from child abuse and the recognition of a variant form. Am J Med Genet 1993;45:18792.

14. Miller ME. Temporary brittle bone disease: a true entity? Sem Perinatol 1999;23:174-
82.

15. Miller ME. The lesson of temporary brittle bone disease: all bones are not created equal. Bone 2003;33:466-74.

16. Paterson CR. Temporary brittle bone disease: fractures in medical care. Acta Paediatrica 2009;98:1935-8.

17. Mendelson KL. Critical review of 'temporary brittle bone disease'. Pediatr Radiol 2005;35:1036-40.

18. Jenny C. Evaluating infants and young children with multiple fractures. Pediatrics 2006;118:1299-303.

19. Paterson CR, Monk EA. Long-term followup of children thought to have had temporary brittle bone disease. Pediatr Health Med Ther 2011;2:55-8.

20. Ablin DS, Greenspan A, Reinhart M, Grix A. Differentiation of child abuse from osteogenesis imperfecta. AJR 1990;154:1035-46.

21. Kemp AM, Dunstan F, Harrison S, et al. Patterns of skeletal fractures in child abuse: systematic review. BMJ 2008;337:859-62.

22. Kleinman PK. Problems in the diagnosis of metaphyseal fractures. Pediatr Radiol 2008;38:S388-94.

23. Offiah A, van Rijn RR, Perez-Rossello JM, Kleinman PK. Skeletal imaging of child abuse (non-accidental injury). Pediatr Radiol 2009;39:461-70.

24. Hiller HG. Battered or not - a reappraisal of metaphyseal fragility. Am J Roentgenol 1972;114:241-6.

25. Kleinman PK, Belanger PL, Karellas A, Spevak MR. Normal metaphyseal radiologic variants not to be confused with findings of infant abuse. AJR 1991;156:781-3.

26. Miller ME. Another perspective on the cause of metaphyseal fractures. Pediatr Radiol 2008;38:598-9.

27. Miller ME, Hangartner TN. Temporary brittle bone disease: association with decreased fetal movement and osteopenia. Calcif Tissue Int 1999;64:137-43. 